\title{
EN HIVER
}

(1999)

\section{Frédéric Torterat}

\section{IMPRESSION}

Le ciel s'est dégagé. Ce matin, presque belle, l'inclémence du temps a laissé derrière elle quelques rayures de morosité, dans sa pâleur trempée de gris bleuté.

L'outremer, l'indigo, le blanc, le bleu de Prusse se suivent à présent - comme si, par astuce, le ciel variait ses coloris, trop plats, pour désapprendre les noirceurs d'en bas.

\section{UNE RIDE}

Regardons un instant dans un miroir limpide : en plus de nos défauts les plus incommodants, il est frappant de voir comme une simple ride donne une forme à nos renoncements.

Venue de nulle part, agile, elle dessine une ligne marquée dont quelques-uns diront qu'elle indique un repli, le tact ou la lésine, tout en ne faisant qu'une avec le front.

Or, il n'y a que nous qui sachions son histoire, nous l'avons vue paraître et grandir peu à peu, et nous sommes si faux que nous voudrions croire qu'elle ne porte en elle aucun aveu.

Mais elle est là, aussi concrète qu'un mensonge, car la ride est plus vraie que le moindre récit : tandis que son tracé se faufile et s'allonge, le temps pour nous se rétrécit. 


\section{DECEMBRE PARISIEN}

Par instants tout ressemble en moi-même, à ces pluies, à ces bruines d'hiver aux odeurs de graviers, et ces paliers couverts de fanes aplaties qui viennent s'entasser au bas des escaliers.

L'horloge, résonnant de sa voix grasseyante, disloquant l'air du temps, rejette dans l'oubli les ressentis fugaces du passé, et tente quelque hoquet poussif qui ne fait rien qu'un pli.

Dehors, sous un ciel fade et tassé qui s'affale, les avenues, aux premiers pas que nous faisons, s'habillent d'un désordre empêtré de gris pâle où s'agitent les cris de ses goitreux pigeons.

Décembre, empli d'hiver et de débris d'automne, a recouvert les toits d'un manteau pourpre et gris ; les cliquetis grinçants de la sourde crémone et les portails rugueux résonnent dans Paris.

On se hasarde moins aux contours des ruelles que dans les galeries marchandes, semble-t-il. Le temps s'est rafraîchi. Des femmes ont sur elles des tricots de coton repassés sur le fil.

L'église Saint-Gervais se rouvre à ses bigotes, les bars et les cafés à leurs garçons bavards, et l'on voit accourir des têtes de linottes aux vitrines écrues des magasins blafards. 


\section{JANVIER}

Voici venir janvier, dans le préau qui craque, dans le battant qui claque, et le piètre papier qui tremble dans la flaque.

Frappant à mes carreaux, la bise, qui marmonne, cinglante, me cloisonne derrière les barreaux de son chant monotone.

Dans le pré graveleux durcit la pierre sèche ; l'hiver, qui se dépêche, l'hiver, rude et frileux, s'immisce dans la brèche.

Le givre y perce un trou que le hasard s'attitre, puis, dans un bruit d'écrou, sa main blanchit ma vitre et bloque mon verrou.

\section{LA VITRE}

Quelquefois, quand il pleut dehors, et qu'un bruit imprévu résonne, juste au moment où je m'endors, comme une voix sourde, brouillonne,

j'imagine que quelqu'un vient ici, vers moi : une personne inquiétante, avec un teint blême, oublieux, et j'en frissonne.

Tout à coup, tout redevient noir.

Plus un bruit, pas même un murmure.

Rien à entendre ni à voir.

L'aube apparaît à toute allure.

Bientôt ma vitre pâlit, em-

buée sur un fond blanc, tout blanc. 


\section{SANS BRUIT}

Tout s'apaise. Elle dort comme un chat, comme en pose, sur le petit sofa qu'arrose

un grand trait de lumière qui va, s'interrompt, et passe tout à coup frôler son front.

On dirait que l'aube est apparue là, souriante, et que, timide, elle patiente,

délassée, assoupie, juste avant de s'ouvrir et de s'épanouir ;

et c'est plus qu'une joie de rester auprès d'elle et de se voir, tant elle est belle,

côtoyer la candeur incarnée simplement, rien qu'un moment.

\section{SCENE D'INTERIEUR}

On y voit peu à l'intérieur, et c'est à peine si le jour apparait à travers les rideaux.

Sur le fauteuil en tissu blanc, un linge en laine est posé en désordre auprès de deux manteaux. Sur la table, il y a un genre de ménisque, des papiers gris, un crayon bleu, un feutre vert, un carnet griffonné, ainsi qu'un tourne-disque qui joue en grésillant des phrases de Schubert. Grisante, la musique appesantit son thème et se déplace dans la pièce d'à côté, tournoyant au-dessus d'une console blême où de grands gerberas forment un aparté. La rumeur du piano vibre, et, brusque, se mêle à celle de la voix qui frôle un accoudoir, et leurs notes liées, qu'aucun tressaut ne fêle, une à une, se faufilent dans le couloir. Mais à l'arrière du salon, sans bruit, sans lampe, une petite alcôve est là, dans un coin noir, réduit sans mobilier où la pudeur se trempe, et où s'est dissipé un air de nonchaloir. Une natte parait. Pressante, elle se glisse dans une main fugace et qui vient la saisir. Et l'ombre grise et nue, empreinte de délice, soupire de l'emprise où s'éclot son désir. 


\section{AUPRES D’ELLE}

Mêlé de pluie, le vent agaçait vos cheveux.

Nous marchions côte à côte, à l'écart de la vente ; je vous parlais, avec des mots si sourcilleux que vous me souriez d'une manière absente.

Je vous flattais, je vous vantais d'un air soucieux. Je vous ai même déclaré que, comme amante, vous pouviez me réduire à vous toucher des yeux, et que l'amour flétrit quand on le bonimente.

En parlant, j'ai mêlé le plus bas ornement à l'imbécillité la plus outrée. Vraiment, j’ai montré de moi-même une si pauvre mine

que j'ai dû ressembler à ceux que j'abomine. Or vous, vous me laissiez vous décrire mon sort, et vous étiez ailleurs, et vous n'aviez pas tort.

\section{LES AMUSEURS PUBLICS}

Les débarras ont tous un pantin goguenard dans un carton plié, tassé, et que l'on fiche au-dessus d'un placard, ou dans un coin très chiche qu'un amas de hochets remplit de toute part.

Voici Gilles, le niais, Pierrot, le pleurnichard, dont les noms quelquefois reviennent à l'affiche, et qui prennent alors leur allure godiche, leur mimique stupide ou leur air cabochard.

Des amuseurs publics, des clowns : tels sont leurs titres ! Or si, dans ce grotesque rôle de grands pitres, ils laissent par malheur échapper de vrais pleurs,

personne n'aura vu ces belles amarantes, car nos pleurs sont bavards, quand le moindre des leurs est à jamais caché sous des joues grimaçantes. 
MADRIGAL

Tout entiers au bonheur d'une amitié candide, nous nous sommes compris bien avant d'être amants, et le monde a souri sans plisser une ride à ces quelques moments.

Amitié, ou amour? nul n'a pu nous le dire sans paraitre grossier, bavard ou déplaisant ; nul n'en a rien décrit, car rien n'a pu décrire un tel emportement.

Aujourd'hui qu'oublié tel un esprit frivole, je reste apitoyé sur un passé perdu, tout me plaint ici-bas, mais rien ne me console de ce que j'ai vécu.

C'en est ainsi, dit-on, d'un amour qui s'agace à vouloir revenir à ce qu'il a été, et qui, avec le temps, nous semble aussi fugace que sa brutalité.

On s'habitue alors au deuil qui nous engonce et qui nous rend l'esprit et la chair éreintés. Ensuite, peu à peu, l'adieu donne réponse à tant d'affinités. 